4. Headache follows both; that of migralne being more severe.

5. The aura of migraine seldom affects a leg or. the trank.

6. Somnolence may occur in both.

As Gowers agys, "It is curlous that the most frequent relation between epilepsy and migraine is as a source of error between the two." Of course, one always has to remember that they are both comparatively common complaints, and there will be a natural overlapplng, apart from any affinity.

The antecedents of migraine are migraine or gout, those of epllepsy belng epllepsy or insaulty. In migraine there Is no deterioration of mind.

\section{THE REMOVAL OF FOREIGN BODIES FROM} THE AIR AND FOOD PASSAGES.

Bx D. R. PATERSON, M.D., M.R.C.P.,

SÜRGRON TO THE EAR AND THROAT DEPARTMENT, CARDIFF IN.IRMARY ; HONORARY SURGEON FOR DISEASES OF EAR AND THROAT,

$$
\text { ROYAL SEAMEN'S HOSPITAL, CARDIFF. }
$$

Amosg the cases of foreign bodies in the air and food passages which came under my department during the last twelve months, two are of special interest, and appear to be worthy of record. While illustrating the ease with which such forelgn bodies can be extracted even from deep-lying sites by means of the direct method, they show, at the same time, the importance in using it of having good illuminating power. They will also serve, I hope, again to call attention to this admirable mode of treatment; as it has hardly received in this country the attention it deserves.

\section{Nutshell in the Left Bronchus-Extraction by} Bronchoscopy.

A young sallor, 18 years old, was admitted to hospital in January suffering from difficuliy of breathing. He was eating nuts whilst playing "leap-frog," and aspirated part of a nutshell into his larynx. He had a severe suffocative attack lasting some time, during which he was partially opanosed and in great distress. After a while the obstruction appeared to become displaced, and, whlle the breathing was reileved, discomfort was felt lower down in the chest. When seen, twelve hours later, he complained of a feeling of constriotion of the chest and cough, and wheezing was audible. Beyond rhonchi heard over the larger air tubes there were no definite rhonchi heard over the larger air tubes there were no definite
physical signs to be made out in auscultation. He was put ander chloroform, which he took rather badly, there being much cough and cyanosis. After the upper part of the respiratory traot had been well cocainized, a Killian tabe $9 . \mathrm{mm}$. In diameter was passed through the largnx into th trachea, which was Injected and intensely red and contained much frothy mucus. This was raplaly removed by means of the saliva pump and cocaine applied to the lower means sages. The tabe was passed down the right bronchus, whtoh was explored as far as the second ramification and found Was explored as far as the second ramification and found
empty. Its mucous membrane was much injected, probsbly explained by the fact that the patient had been suffering from " "bronchial cold" for some days. In searching the left bronchus a mass, reddish in colour, was fonnd blocking it jast bslow the commencement, but lts relations were difficalt to make out owing to the insufficient lllumination given by a worn-out lamp. The examination was accordingly suspended, and on the following dey the patient was agsin plased under the influence of chloroform, which he this time took very well. Using a new lamp giving a greatly-improved light, I passed the tube at once down to the left bronchus, I passed the tube at once down to the left bronchus, was made out to be the plece of nutshell lying inslde the bronchus having a small hook-like process over the bifurcetion. The convexity of the shell was uppermost, and from ander it a constant stream of frothy mucus poured out of the bronchus. Its.red colour closely resembled that of the adjacent mucous membrane, and it was the greyish tint of the part of the'shell next the blfarcation which enshled its exset part of to be recognized. A Killian long forceps was passed down the hooked end was seized and the noreps was passed down, the hooked end was seized and the nutshell drawn out along with
the tube. The whole procedure did not last more than a the tube. The whole procedure did not last more than
quarter of an hour. The patient left hospital two days later.

The object removed was a Iragment of a Spanish nutshell measuring $2 \mathrm{~cm}$. by $1.6 \mathrm{~cm}$. (Fig. 1). Its outer smooth conver surlace was of a unlform red colour resembling that of the bronchial mucous membrane. Towards the apex, where it terminated in a hooklike process, it had more of a greyish tint, and this was the only point which stood out in contrast to Its surroundings. Foreign bodies in the bronchl usually become covered with mucus and ass ume a grey appearance which renders their identification from the adjacent structures easy; but in this case the polished surface of the shell afforded no hold to a mucous covering, and the entrance of the bronchus looked at first sight as it it were

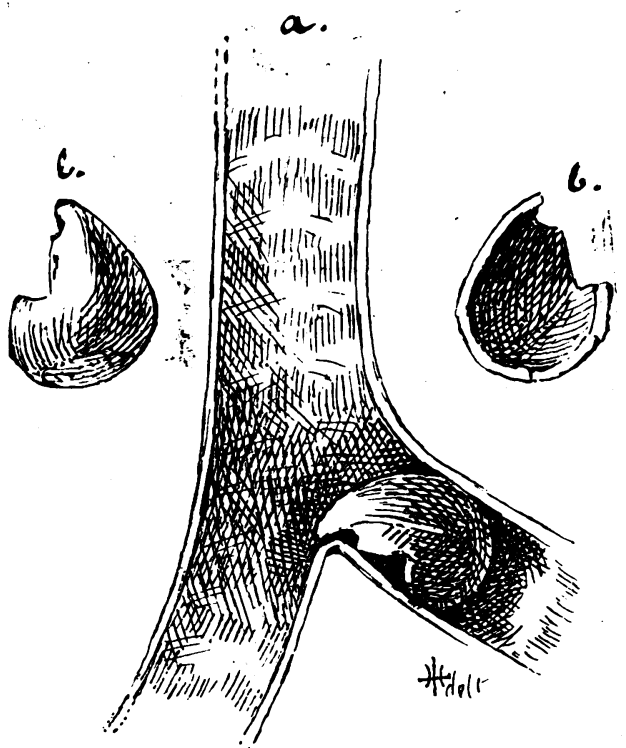

Fig. 1.-Nutghell (a) impacted in left bronchus; (b) after removal.

filled by a smooth globular swelling. The use of a good light soon revealed, however, the condition of things; and, the exact relations having been ascertained by means of a probe, the extraction presented no special difficult?.

Plum Sione in the Oesophagus: Removal by Oesophagoscopy.

A Norwegian sailor, aged 16, was admitted in June, 1907, with diffionlt in swallowing 80 complete that nothing had been passed for forty-elght hours. There was a complete block of passed for forty-etght hours. There was a complete block of the gallet, and this had come on atter swallowing a plum stone. Attempts to dislodge it had been made cess. On admission the resident medical officer passed soft bougies, and found that a small size could be got as far as the cardisc end of the oesophagus, where it stopped, and a large slze was arrested about the middle of the chest. He wisely refrained from employing any force or using a coln-catcher. The patient was placed under chloroform, and an oesophagoscopio tube of $13 \mathrm{~mm}$. dismeter passed down an oesophagescopic tube of $13 \mathrm{~mm}$. dismeter passed down until it was stopped about 8 in. from the teeth by a narrowing of the gullet, which was emphasized by spasm. But even abolition of the spssm under deep ansesthesia did not permit its passage. Accordingly a tube of $9 \mathrm{~mm}$. diameter was introduced, and this went through the narrow part without diffculty. It was carried as far as a short distance above the cardlac orifice 12 in. from the teeth, where the plum stone was found lying transversely across the gullet. The mucus was wiped away, and the exact relations of the body ascertained by the probe. It was readily grasped by the forceps, and was being drawn up along with the tube, into which, and was being drawn up along with the tube, into which, on account of its size, it could not enter, when it stuck at the narrow part and the forceps slipped. This bappened
twice. By a little manipulation the plum stone was turned twice. By a little manipulation the plum stone was turned lengthwise and then grasped, after which it was mar cavred through the constriction and brought out along with the tabe. We subsequently learned that the patient when a child had careful in eating. A few years ago ho had trouble with food which remained in the oesophagus for several days.

The size of the fruit stone extracted (FIg. 2) was $2 \mathrm{~cm}$.

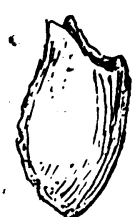
by $1.2 \mathrm{~cm}$. It had a sharp hook-llke
process at one end. This was embedded In the mucous membrane of the cardis and a forcible attempt to push down the stone would certainly have led to laceration. As a rule a forelgn body is easily recognized, standing out, as it generally does, in sharp contrast to the Fig. 2. - Plum pink tint of the mucous membrane. In stone extracted this instance, again, the red colour of the from cardiac end forelgn body gave no such distinction, of oesophagus. - Iorelgn body gave no such distinction, brilliant illumination was indlspensable.

The general technique of the method of removing forelgn bodies by bronchoscopy and oesophagoscopy I have already 
dealt with elsewhere, ${ }^{1}$ and it is unnecessary to refer to it here. It is of interest to note that aince Killian published his first cases of forelgn bodies removed by bronchoscopy, nine years ago, more than 200 cases have already been recorded in medical literature. They all teach the importance of undertaking extraction at an early period, and more especially is this true of soft bodies, such as beans, etc., which swell and are prone to start septic trouble in the lung. The cases published in this conntry are still very few in number. We have the old methods still in practice. Articles in our journals continue to advocate tracheotomy as the proper treatment, in the hope that the foreign body may be coughed up, and failing that, to grope blindly with a forceps or wire loop. It seems to me that the direct method points the way that best carries out surgical principles, and is at once sale and practicable; and it behoves the profession to bring itself into line with the real progress which has taken place in this important branch of surgery.

REFERENCE.
BRITISH Medicat JOURNAL, 1906, vol. ii, p. 353.

\section{MEMORANDA : \\ MEDICAL, SURGICAL, OBSTETRICAL.}

a CASE OF PYREXIA IN MALIGNANT DISEASE SUGGESTIVE OF SUPPURATION.

Dr. J. W. Rosskrl's Instructive paper on temperature in mallgnant disease of the liver and blle paszages ${ }^{1}$ renders It desirable that simllar cases should be placed on record. The patient in the present instance was a man of 64 , who had always enjoyed good health untll about two years ago, when he began to lose flesh and noticed increased frequency of micturition. In January, 1906, he had a severe attack of pain in the abdomen and right slde simulating biliary colic, and a similar attack occurred in November of the same year. He had never suffered from jaundice or from any dyspeptic symptoms.

State on Examination.-When I gaw him in January, 1907, he was complaining of severe abdominal pain and tenderness, the latter being specially localized opposite the tjp of the tenth rib. His temperature showed remarkable variations throughout the illness, but there were no rigors and no jenndice, and romiting, though it occurred occasionally, was never an urgent symptom. The liver showed some general enlargement bat no nodules could be distinguished, and no enlargement, bat no nodules could be distinguished, and no enlargecontained a considerable quiantity of sugar (26 grains per ounce). Carefal examination of the abdomen falled to reveal any evidence of tumour growth, nor could any enlarged glands be discovered. The faeces were of a pale greyish-white cjlour, and on more than one occsslon were of the paltaceous character typical of pancreatic disease.

The temperature chart which I append is strongly suggestive

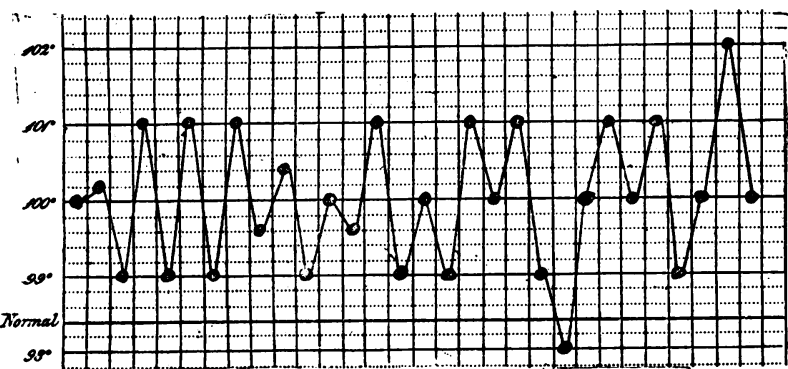

of supparation, and it required most carefal and repested examination to convince myself that none existed; the leacocyte count, which was only 5,700, confirming this leucocyte

Autopsy. - The patient died on February 20th from acute haemstemesis, and I was fortunate enough to obtain post-mortem examination. This revealed cancer extending throughout the pancreas, involving the adjacent portions of the stomach, and with secondery growths in the liver, especially the right lobe. There were no gall stones, no chole opgtit peritonitic adhesions betwesn the diaphragm and the right peritonitic adhe

REMARKs. - This case forms a good illustration of Dr. Russell's contention that rise of temperatare simulating suppuration may take place in malignant disease of the Iiver in cases where there is nelther suppuration nor BRITISH MEDical JoURNAL, 1907, vol. i, p. 311. cholelithlasis. The resemblance was rendered all the closer in this particular case by the frequent occurrence of early morning perspiration. That this rise of temperature is due to some form of toxaemia can scarcely be doubted. Possibly it is of intestinal origin, and due to the entrance into the clrculation of toxins which the liver, rendered hors de combat by cancerous infiltration, is no longer able to antagonize.

Bolton. W. H. BraziL

\section{A CASE OF TWINS WITH HYDRAMNIOS} OF ONE SAC.

C. L., a 3-para, was brooght in from the country. She was six months pregnant, and was distended to the ensiform cartilage. She presented all the features of a large hydramnios, and on the second day after my ceelng ber the os began to dilate, and the head of a child was felt distinctly without the intervention of a bag of membranes. As labour was very slow, when the os was well dilated I turned and delivered a dead female child; no llquor amnii came away, and the size of the uterus was not appreciably reduced. I then Inserted my hand into the uteras and found an enormons bag of membranes quite intact, and with another child floating freely within It. Upon puncturing the membranes about 2 gallons of liquor amnil was evacuated, and I withdrew another dead female child. The uterus quickly contracted, and the single placenta was soon expressed.

The point of interest In the case was the absence of the fluid around the one child and its great abundance and entire l/mitation to the amniotic sac of the other.

Grahamstown, C.C. J. .BRUCE-BAYs, M.D.Lond.

\section{REPORTS$$
\text { on }
$$

\section{MEDICAL AND SURGICAL PRACTICE IN THE HOSPITALS AND ASYLUMS OF THE} BRITISH EMPIRE.

\section{BRADFORD CHILDREN'S HOSPITAL,}

CASE OF STRANGULATED INGUINAL HRRNIA IN AN INFANT

29 DAYS OLD : OPERATION : RHCOVRRY.

(Reported by William H. Thompson, M.R.C.S., Honorary Surgeon.)

J. B, aged 29 days, was admitted on January 7th suffiting from a swelling in the right side of the scrotum.

History.--Up to January 6th the chlld had been quite well, but during the night he began to vomit. The vomiting continued untll the morning, and the mother noticed the swelling in the right side of the scrotum about noon. So far as she is aware there had been no swelling there before. She took the child to Dr. Kee, who diagnosed strangulated inguinal hernla, with faecal vomiting and ordered its removal to hospltal.

On Admission. - The child was quiet, but looked extremely ill. In the right olde of the scrotum was a large, tense swelling, which extended up through the inguinal canal. The \&kln over the swelling was red. The swelling was irreducihle. The abdomen was only alightly swollen and ty mpanitic, and rigidity was not marked.

Operation.-An hour after admission (7 p.m.) the child was operated upon. The usual Incislon was made over the tumour, and the sac exposed; on this belng opened blood-stalned serum escaped. A coll of small intestine, quite black in colour, was found tight]y strangled at the neck of the sac. The constriction was divided, and the bowel palled down for a short distance and examined. The hernis was then easily returned, the sac removed, the Internal abdominal ring closed with sutures, and the operation completed as usual.

After-progress. - Recovery was uneventful, with the exception of sllght retentlon of urine for the first day alter operation. At the end of filteen days the child was com. pletely well and was discharged from the hospital.

REMARK8.- I have thought the case worthy of record owing to the very early age of the patient and the ex. tremely satisfactory result of the operation. I am indebted to the Honse-Eurgeon (Dr. G. Young) for the notes of, and his carelul attention to, the case. 